\title{
The Philosophical Foundation of Public Crisis Opinion Flexible Management
}

\author{
Kun Liu \\ School of Management, Wuhan University of Technology, Wuhan 430070, China
}

Keywords: the public crisis opinion, flexible management, history and culture.

\begin{abstract}
The transmutation of social context and media ecology has injected an uncertainty into the public crisis opinion, which leads flexible management to be a better way. As a stretcher and more flexible managing thought, flexible management prevails particularly in the west, whose essence roots in the same vein with Chinese cultural traditions. From the perspective of history and culture, this thesis, consisting of the spiritual core of people-oriented, the choice of governing by noninterference, the principle of adjusting measures to local conditions and the behavioral request of applying law and etiquette, explores and analyzes the cultural origins of flexible management, and expounds the unique advantages of the public crisis opinion flexible management.
\end{abstract}

\section{Introduction}

At present, the transformation of human society, the quick changes of media technology and the game of multiple values make the age full of uncertainties, which is extending to all aspects of social fields. Given by the instinct of pursuing interests and avoiding risks, the effective management conducted by people to uncertain social situations becomes an urgent affair.

Different management concepts will lead to the differences of managing modes and their effects. Should it be flexible adaption according to the environmental changes, or be refusal to change because of defending tenaciously mindset? Some experts have pointed out that changes and developments are shouting for flexible management. The public crisis opinion management should make a balance or choice between Rigidness and the more flexible as well. Comparing with the traditional rigid management which pursuing stability and identity, the flexible management of public crisis opinion which can finally achieve the goal of leading and dispelling crisis opinions after making buffering, adapting and innovating changes and then coordinating the relationship with other subjects according to the multiple, changeable, complex and polyphyletic features of public crisis opinion, is obviously superior.

Flexible management like this is flexible and stretchy. Although flexible management is an imported good which doesn't originate from our nation, it has a same pulse with Chinese Confucianism and management thoughts referring to its historical culture origins and philosophical foundations.

\section{People-Oriented Spiritual Core}

People-oriented, is also the traditional Chinese People-based Thought. It is originally recorded as "People are the only foundation of a nation and a nation can be stable only when the foundation is stable", in the Song of Five Children, written by Taikang, who was the grandson of Yu, the monarch of Xia Dynasty.

After that, it has been one concept pervading all things in the Confucian management ideas that people is the foundation of a nation. Confucius pointed out "People view the monarch as the center while the monarch views the people as the foundation". Xuncius thought,"The monarch is like a boat while the people are like water and the boat can be floated by the water but can also be overturned by it". Menci pointed out, "People are the most important, followed by the state, and the least is the king”. Chun Qiu Annals: Gu Liang Zhuan said, "People are the foundation of a nation". People-based thought was abandoned in the Qin Dynasty. However, with the development of history, people approve this thought further. Jia Yi, a politician in the dynasty of Xi Han, not only stressed, "Nations, 
monarchs and government officers should regard people as the foundation", but also pointed out, "People master the safety of a nation, the prestige of a monarch and the dignity of government officers". Li Shih-min, the emperor of Tang Dynasty, learned from the perishment of Sui Dynasty and concluded, "The duty of an emperor is to enable people to survive".

It is clear that in all ages, managements have been striking for the respects and consideration of the people. In public crisis opinion management, this concept, which is full of the more flexible, can be favorable for people to bring subjective initiative into play to better coordinate the behavioral relationship among the government, the media and the public. Hence, each part in the management can stay flexible, which can achieve an interaction with the object environmental changes and promise the management to operate regularly.

\section{Governing With Non-Interference}

The root meaning of governing by non-interference is self-actualization. Lao Zi, the founder of the Taoist school, once said, "Tao seems to attempt and accomplish nothing, however, it actually gets involved in everything in the world...everything can spontaneously grow and develop". This doesn't mean to be negative or doing nothing, however, it actually stresses to follow rules and the nature, and to reduce the managing actions in the organized system and the human intervention to social life as much as possible, in order to invoke the self-managing energy and ability of the society.

To survey comprehensively, many dominators in ancient China were acquainted with the way of governing by non-interference. Kangxi once said, "From the old times, the best way to make people live well is not to disturb them. It's better to save trouble. I find out that in the past days, once officers craved for greatness and success, a nation would waste man power and money so that the nation would be trapped in a mess. Therefore the people would gradually feel scary. We definitively have to learn this lesson". Kangxi's words reflect a brilliant philosophy of managing with doing nothing. Meanwhile, governing with non-interference stresses that managers should cultivate lofty moral and the way of self-discipline and stabilizing others in order to let people convert the external regulations into internal commitment and action consciousness.

Not only Lao Zi, but also Confucius said, "The governors' moral character is like winds while people's like grasses. Once the winds become strong, the grasses will fall down". This means that the managers can lead people to follow their example so that they can achieve an effect of doing nothing by having good moral integrity.

To summarize, the essence of governing with non-interference is to endow human with maximum autonomous right, to externalize the code of humanistic management, and to revere an optional managing method. In the field of public crisis opinion flexible management, the key reflection is to change the government's arbitrary image, and to release more managing powers to the public to enhance their participation and values in the managing activities.

\section{The Principle of Adjusting Measures to Local Conditions}

Chinese Confucianism especially focus on this principle. Huainan Zi: Fan Nan Xun pointed out, "Instruments should be developed over time to adapt to new requirements". Pang Xuanling in the Tang dynasty also said, "Chance is always changing, so it is essential to carry out proper measures according to different situations in order to make the things better". Wei Yuan, living in the Qing dynasty, said in the Sheng $W u$, "The most important thing for dealing with governmental affairs is to adjust measures to local conditions". From all these recordings, it can be seen that the management in ancient China pays fully attention to changes while avoids invariability, which means to adapt a flexible management in the changing environment.

Jia Yi, who lived in Western Han Dynasty, has a specific managing principle of changing over time. He learned from the disruption of the Qin dynasty and said, "Someone who urges to take over the other nations advocates for powers and violence while someone who urges to maintain a nation needs to comply with the aspirations of the people, which means conquering and maintaining need different strategies. After Qin conquering the other six countries, the emperor kept the strategy to 
guard this nation which was used to conquer territories". This makes it clear that conquering and guarding should be changeable over time.

In the book Xin Shu: Qin's Faults, Jia Yi pointed out, "A monarch needs to acknowledge the rules of rising and falling by referring to histories, testing the in contemporary age and personnel matters, and identifing if the strategy match to the time, so that he can develop an appropriate strategy to keep the nation stable". This view is full of creation, which stresses not only that managing strategy should be tested in the contemporary age and personnel matters, but also that managing activities must take history as a mirror. This idea is of great advantage for the modern public crisis opinion management. Only in the modern flexible managing way with the historical experiences can managing activities be adjusting measures to local conditions to reduce or to avoid blindness in order to increase managing benefits and success rates.

\section{The Behavioral Request of Applying Law and Etiquette}

This is the guideline in more flexible management. Confucian Xuncius in the Warring States Time set up the managing thought of advocating etiquette and respecting laws. On the one hand, human's destiny is decided by God while a nation's destiny is decided by laws and etiquette. The Etiquette is the generic terms of ethics and rites, which governing the interpersonal relationship and the one between people and the society. On the other hand, Xuncius found out that the morality was not a panacea. Depending on morality to edify people is not sufficient. When stressing the rule of virtue, it is important to stress the rule of law. He though "keeping both law and virtue" and the virtue was the basis of the law while the law was set up for maintaining the virtue.

Thereafter, Xunciun's students like Han Feizi and Li Si only partly accepted the thought of "human nature is evil" and they are true believers of managing a nation by law. But Jia Yi in Western Han Dynasty insisted on rule of both law and virtue. He realized that law was the basis and precondition in managing. In a more and more complex social organization, each managing activity cannot be divorced from legal institution to ensure a gubernatorial authority and strict enforcement of orders and prohibitions. Meanwhile, he showed exceptionally appreciation for the rule of virtue and thought "The virtue can be used to establish a nation and a society, enabling the monarch to keep his people". The virtue can settle people's disputes from the moral aspect, so that each role is in his proper place and the relationship can be harmonious.

Thus it can be seen that in Chinese traditional flexible management, the law is the basis and promise for a successful managing activity while the virtue is the gist and practice presents which can affect a managing results. Once the law and the virtue are divided, neither of them can work well. The law is rigid while the virtue is flexible. And they restrict but supplement each other, which are the two essential elements and tools to ensure a successful managing activity. Cooperation can bring benefits while opposition will block it. To be specific, in the public crisis opinion management, it is right to coordinate the rigidness and the more flexible according to the real situations instead of choosing alternatively.

To have an overview of Chinese traditional managing thoughts, it is clear that although the managing thoughts were various, all of these thoughts were keeping on chasing for the exploration of being human and handling affairs. From the aspect of being human, most Chinese ancient thinkers showed their focuses on kindness, righteousness, propriety, wisdom, and trust. They strove to win people by virtue, and further to solve interpersonal conflicts and the one between human and objects so that they could reach harmonious. It can be spoken that kindness, righteousness, propriety, wisdom, and trust are methods that emphasize flexible management, which are the mainstream thought of Chinese traditional management. From the aspect of handling affairs, Chinese ancient managing thoughts showed more focuses on moderation and inaction. Governors strove to make a balance and consider the situations. Meanwhile, they were following the rules of the nature and stressing on selfgovernment and self-actualization to stimulate people's innovation so that a harmonious statecan achieve.

On this basis, we can sketch out that Chinese ancient flexible managing thoughts have brought tow positive aspects for the modern public crisis opinion flexible management. On the one hand, 
Chinese ancient flexible managing thoughts have been the great cultural genes for modern thoughts of public crisis opinion flexible management. On the other hand, based on this, not only traditional and modern thoughts of flexible management can be blended, but also Chinese and western thoughts of managing public crisis opinion can communicate to each other.

\section{References}

[1]. Wu Yiming. The popularization of higher education calls for flexible management [J] .China Adult Education, 2001(8): 10-11.

[2]. Xu Xingdong. Interpretation of Tao Te Ching[M].Shandong:Qilu publishing house,1991.

[3]. Xiao Yishan. History of Qing Dynasty [M].Beijing: Zhonghua Book Company, 1986.

[4]. Yan Xiumin.Jia Yi's Soft Management Thoughts [J].Journal of Jianghan University, 2005(3):60.

[5]. Hu Wenzhen. People-oriented and Soft Management [J].Academic Communication, 2008(12): 167.

[6]. Liu Zhenjiang, Tang Changhong, Yi Jingsheng. Philosophical Thinking of Law-based and Virtue-based Governance [J].Hunan Social Sciences, 2001(4): 20-22.

[7]. Zheng Qixu. Soft Management [M].Jinan: University of petroleum press, 1996:92.

[8]. Liu Kun.The Code and Value of Public Crisis Opinion Soft Management [N].Guangming Daily, 2015-11-28(6).

[9]. Han Dayong, Ye Fucheng. The Wisdom of Soft Management [M].Beijing: China Economic Publishing House, 2012: 10. 